\title{
Increased number of mast cells in the bone marrow of chronic myeloid leukemia may herald the pending myeloid transformation - the mast cell is an indicator of myeloid transformation
}

\author{
Peipei Xu" ${ }^{1 \#}$, Cuiling Zhang ${ }^{1 \#}$, Yushan Wang ${ }^{1 *}$, Hongyan $W^{2}{ }^{2}$, Shuwen Cheng ${ }^{1}$, Xiangshan Fan ${ }^{2}$, \\ Qiguo Zhang ${ }^{1,3}$
}

${ }^{1}$ Department of Hematology, ${ }^{2}$ Department of Pathology, The Affiliated Drum Tower Hospital of Nanjing University Medical School, Nanjing 210008, China; ${ }^{3}$ Department of Hematology, The First People's Hospital, Chuzhou 239000, China

Contributions: (I) Conception and design: P Xu; (II) Administrative support: Q Zhang; (III) Provision of study materials or patients: X Fan; (IV) Collection and assembly of data: Y Wang, C Zhang; (V) Data analysis and interpretation: H Wu, S Cheng; (VI) Manuscript writing: All authors; (VII) Final approval of manuscript: All authors.

\#These authors contributed equally to this work.

Correspondence to: Qiguo Zhang, PhD. Department of Hematology, The Affiliated Drum Tower Hospital of Nanjing University Medical School, Nanjing 210008, China. Email: qgzhang8@sina.com.

Background: Tumor cells are surrounded by many inflammatory cells, including mast cells (MCs), which can secrete several classic proangiogenic factors, resulting in endothelial cell proliferation and angiogenesis. However, the researches of the number of MC and microvessel density (MVD) in the bone marrow in chronic myeloid leukemia (CML) are rare. In this study, we aimed to investigate the relationship between tryptase-positive MCs and MVD in the different phases of CML.

Methods: Bone marrow samples of 61 patients with CML and 20 healthy donors were collected from 2007 to 2017. Antibodies against the endothelial cell marker CD34 and against tryptase were used in immunohistochemistry. The diagnosis and counting of tryptase-positive MC and microvessel in bone marrow was at $\times 400$ magnification.

Results: MVD in CML group was higher than which in the control group, and the blast phase (BP) group had a higher MVD than which in chronic phase $(\mathrm{CP})$ group $(\mathrm{P}<0.05)$. The number of MCs in three groups of CML was higher than which in control group, and the number of MCs in AMLT group was highest $(\mathrm{P}<0.05)$. Patients with a lower grade of tryptase-positive MCs in CP group survived longer OS and PFS $(\mathrm{P}<0.05)$.

Conclusions: The number of MCs and MVD might be markers for the outcome of patients with CML in the Chinese population.

Keywords: Chronic myeloid leukemia (CML); mast cell (MC); microvessel density (MVD); tryptase

Submitted Jun 04, 2019. Accepted for publication Sep 03, 2019.

doi: $10.21037 /$ tcr.2019.09.29

View this article at: http://dx.doi.org/10.21037/tcr.2019.09.29 


\section{Introduction}

Chronic myeloid leukemia (CML) is a myeloproliferative neoplasm with an incidence of 1-2 cases per 100,000 adults and accounts for approximately $15 \%$ of newly diagnosed cases of leukemia in adults (1). The disorder typically progresses through 3 phases: the chronic phase (CP), the accelerated phase (AP), and the blast phase (BP). Allogeneic bone marrow transplantation is currently the only proven cure for CML. However, it is an option only for patients with good performance status and organ functions, and who have an appropriate donor (2). Without effective therapy, most cases of CML progress from $\mathrm{CP}$ to $\mathrm{BP}$ (directly or via $\mathrm{AP}$ ) within 3-5 years after diagnosis. Due to the success of tyrosine kinase inhibitor therapy, the incidence of AP and $\mathrm{BP}$ has decreased, and the 10-year overall survival rate for CML is $80-90 \%$. It is urgent to find other targeted medications and monitoring indicators of CML. The rate of development of and the growth of the tumor is regulated by a delicate balance between pro- and anti-tumorigenic effects, stimulated by the tumor cells themselves, as well as the surrounding microenvironment (3).

Tumor cells are surrounded by an infiltrate of inflammatory cells, namely, lymphocytes, neutrophils, macrophages and mast cells (MCs), which synergize with stromal cells and malignant cells in a paracrine manner (4). As a consequence, there is a stimulation of endothelial cell proliferation and the formation of blood vessels $(5,6)$. MCs can secrete several classic proangiogenic factors, including vascular endothelial growth factor (VEGF), fibroblast growth factor-2 (FGF-2), thymidine phosphorylase, and a nonclassical proangiogenic factor named tryptase, which is stored in the secretory granules of the MCs (7). Tryptases play essential roles in angiogenesis, such as extracellular matrix degradation, plasminogen activation, fibrinogen degradation, latent collagenase and matrix metalloproteinase (MMP) activation, and tryptase-induced endothelial barrier dysfunction (8).

Increased angiogenesis has long been recognized in various types of hematologic malignancies, including CML. Many studies have shown that in multiple myeloma, B-cell non-Hodgkin's lymphoma, and myelodysplastic syndrome, the bone marrow of B-cell chronic lymphocytic leukemia patients and the number of MCs are significantly correlated with microvessel density (MVD), and the two indexes increased simultaneously with increased tumor malignancy (9-12). However, the correlation between the number of tryptase-positive MCs and the MVD in the bone marrow of
CML patients is rarely reported.

In this study, we aim to describe the relationship between tryptase-positive MCs and MVD in the different phases of CML and to determine whether the two indexes affect the development of CML. Moreover, new parameters for the prognosis of CML patients may be found in this study.

\section{Methods}

\section{Patients}

This study examined material that consisted of formalinfixed tissue specimens taken from 61 patients treated in the hematology department of the Affiliated Drum Tower Hospital of Nanjing University medical school in Nanjing, China, from 2007 to 2017 and taken from 20 healthy bone marrow donors. The patient group consisted of 61 patients aged from 14 to 83 years (average, 49). There were 28 men and 33 women, giving a male: female ratio of $1: 1.18$. The healthy control group consisted of 20 healthy bone marrow donors aged from 21 to 50 years (average, 45) and included 9 men and 11 women, with a male: female ratio of $1: 1.22$. Clinical data were collected by reviewing the patients' charts and was part of the clinical database of the hematology department of the Affiliated Drum Tower Hospital of Nanjing University medical school. All the cases were reclassified according to the updated WHO classification. The treatment was either standard or consistent with the investigational protocols active during the time the patients were diagnosed. All of the patients provided informed consent for data analyses in compliance with the Declaration of Helsinki and the Ethics Committee of our hospital.

The patient group was divided into 3 additional groups, including the CP $(n=27)$, the AP $(n=14)$ and the BP $(n=20)$. The BP group was further divided into an ALL transformation group (ALLT) $(\mathrm{n}=6)$ and an AML transformation group (AMLT) $(\mathrm{n}=14)$.

\section{Immunobistochemistry}

The methylmethacrylate-embedded tissue specimens were cut in $3 \mu \mathrm{m}$ thick sections. Two murine monoclonal antibodies (MAbs) against the endothelial cell marker CD34 and against tryptase (Mab AA1, Maixin Company, Fuzhou, China) were used. The prepared bone marrow specimens were placed in citrate ( $\mathrm{pH}$ 6.0) and EDTA9.0 for highpressure heat recovery. After natural cooling, the specimens 
Table 1 Tissue density of microvessels and tryptase-positive cell populations

\begin{tabular}{|c|c|c|c|c|c|}
\hline \multirow{3}{*}{ Number of } & \multirow{3}{*}{$\begin{array}{l}\text { Healthy control } \\
\text { group, } n=20\end{array}$} & \multicolumn{4}{|c|}{ Chronic myeloid leukemia patients } \\
\hline & & \multirow{2}{*}{$\mathrm{CP}, \mathrm{n}=27$} & \multirow{2}{*}{ AP, $n=14$} & \multicolumn{2}{|c|}{ BP, $n=20$} \\
\hline & & & & AMLT, $\mathrm{n}=14$ & ALLT, $n=6$ \\
\hline Microvessels, per $40 \times \mathrm{HPF}$ & $3.13 \pm 1.22$ & $12.90 \pm 3.76^{\dagger}$ & $14.55 \pm 4.77^{\dagger}$ & $27.12 \pm 3.83^{\ddagger \S}$ & $23.00 \pm 2.21^{\ddagger \S}$ \\
\hline Tryptase-positive mast cells, per $1 \mathrm{~mm}^{2}$ & $11.00 \pm 4.13$ & $63.35 \pm 20.42^{\ddagger}$ & $89.08 \pm 36.10^{\dagger}$ & $307.15 \pm 86.23^{\dagger \S}$ & $18.00 \pm 3.22^{\S}$ \\
\hline
\end{tabular}

${ }^{\dagger}, \mathrm{P}<0.05 ;{ }^{\ddagger}, \mathrm{P}<0.01$ vs. healthy control group; ${ }^{\S}, \mathrm{P}<0.05$ vs. CP. CP, chronic phase; AP, accelerated phase; BP, blast phase; AMLT, acute myelocytic leukemia transformation; ALLT, acute lymphoblastic leukemia transformation.

were rinsed twice with PBS and were then dropped in 3\% $\mathrm{H}_{2} \mathrm{O}_{2}$ to block endogenous peroxidase. After rinsing 2 times in PBS, 1:100 anti-tryptase monoclonal antibody and antiCD34 antibody were added and incubated at $4{ }^{\circ} \mathrm{C}$ overnight. After rinsing the specimens 2 times in PBS, the secondary antibodies were added and incubated for $30 \mathrm{~min}$ at room temperature. And the slides were then stained with $\mathrm{DAB}$, counterstained with hematoxylin, dehydrated, cleared, and mounted.

\section{Microvessel counts}

The diagnosis and counting of bone marrow microvessels were based on the Weider method, which recognizes the endothelial cells or endothelial cell clusters that are stained brown by the CD34 antibody and are separated from nearby vessels and bone trabecula during the count of microvessels. The three most vascularized areas ("hot spots") were selected at $\times 100$ magnification, and the microvessels were counted at $\times 400$ magnification. The means \pm 1 standard deviation (SD) and the medians were determined for each section, sample, and group of samples.

\section{Tryptase-positive MCs counts}

In the diagnosis and counting of tryptase-positive MCs in bone marrow, the brown-stained cytoplasm and granules under the microscope were considered positive cells. The MCs were counted in $6410 \times 10$ mesh eyepiece micrometer $\times 400$ fields inside a square reticulum $\left(1 \mathrm{~mm}^{2}\right)$ and were calculated as the means (1 SD and median for each group of samples).

\section{Statistics}

Mean values \pm 1 SD of all the evaluated tissue parameters are reported in Table 1. The significance of the changes in the counts of the MVD and the tryptase-positive MCs was assessed with a parametric (Fisher test) and nonparametric (Kruskal-Wallis test) analysis of variance, followed by the Duncan ( $\mathrm{t}$ ), Bonferroni (t), and Wilcoxon tests, to compare groups. The Kaplan-Meier method was used for survival analysis. Correlations between MVD and tryptase-positive MCs were calculated using Spearmen's ( $r$ ) analysis. $\mathrm{P}<0.05$ was considered significant. All the statistical analyses were performed with the SPSS 11.0 statistical software package.

\section{Results}

\section{Patient and bealthy control group characteristics}

The basic information of the patients and the healthy control group in this study is summarized in Table 2. The patient group included 28 men and 33 women with an age range of 14 to 83 years (median 49 years). Nearly half of the patients $(44.3 \%)$ were diagnosed in the CP, $22.9 \%$ of patients in the AP and $32.8 \%$ of patients in the BP $(23.0 \%$ in AMLT phase and $9.8 \%$ in ALLT phase). The healthy control group consisted of 9 men and 11 women with an age range of 21 to 50 years (median 45 years).

\section{The expression of tryptase-positive MCs in the bone marrow}

In the healthy control group, the expression of tryptase in bone marrow was seen in MCs, and most of the expression was distributed in the main body of the bone marrow and were also located around vessels. The tryptase markers were located in the cytoplasm, and those in the nuclei were covered with the cytoplasm. There were diverse positive cells, some of which were similar to tadpole cells (Figure 1). The tryptase-positive cells of the CML patients were scattered through the central part of the bone marrow, and 2 to 3 cells were occasionally observed in small clusters; no large clusters were found (Figure 1). There were more tryptase-positive MCs in the bone marrow of CML patients 
Table 2 The characteristics of CML patients and the healthy control group

\begin{tabular}{lcc}
\hline Characteristics & CML patients & $\begin{array}{c}\text { Healthy bone } \\
\text { marrow donors }\end{array}$ \\
\hline Number & 61 & 20 \\
Age (median, range) & $49(14$ to 83$)$ & $45(21$ to 50$)$ \\
Gender, N (\%) & $28(45.9 \%)$ & $9(45 \%)$ \\
Male & $33(54.1 \%)$ & $11(55 \%)$ \\
Female & \\
Phase of disease, N (\%) & - \\
CP & $27(44.3 \%)$ \\
AP & $14(22.9 \%)$ \\
BP & $20(32.8 \%)$ \\
AMLT & $14(23.0 \%)$ \\
ALLT & $6(9.8 \%)$ \\
\hline
\end{tabular}

CML, chronic myeloid leukemia; CP, chronic phase; AP, accelerated phase; BP, blast phase; AMLT, acute myelocytic leukemia transformation; ALLT, acute lymphoblastic leukemia transformation. than in healthy controls, and this number increasing with the progression of the disease and peaked in AMLT group $(\mathrm{P}<0.05$ vs. control group and $\mathrm{CP}$ group) (Table 1). The increasing number of MCs in bone marrow along with the development of CML may herald the transformation of CML into AML. The number of tryptase-positive MCs may play a role as a new monitoring indicator of CML.

\section{Vascular morphology and MVD in the bone marrow}

The healthy control group had straight blood vessel morphology and less vascular branches (Figure 2). The morphology of the blood vessels in patients with CML was as follows: (I) irregular vessels with large branching vessels; (II) sinus veins; and (III) small vessels without a lumen (budding of endothelial cells). The MVD in the CP was more than that in the healthy control group, and the vascular branching was increased significantly. The BP had a smaller vascular lumen diameter than the $\mathrm{CP}$, and the blood vessels appeared more round (Figure 2). The MVD in CML patients increased with the evolution of the disease (Table 1).
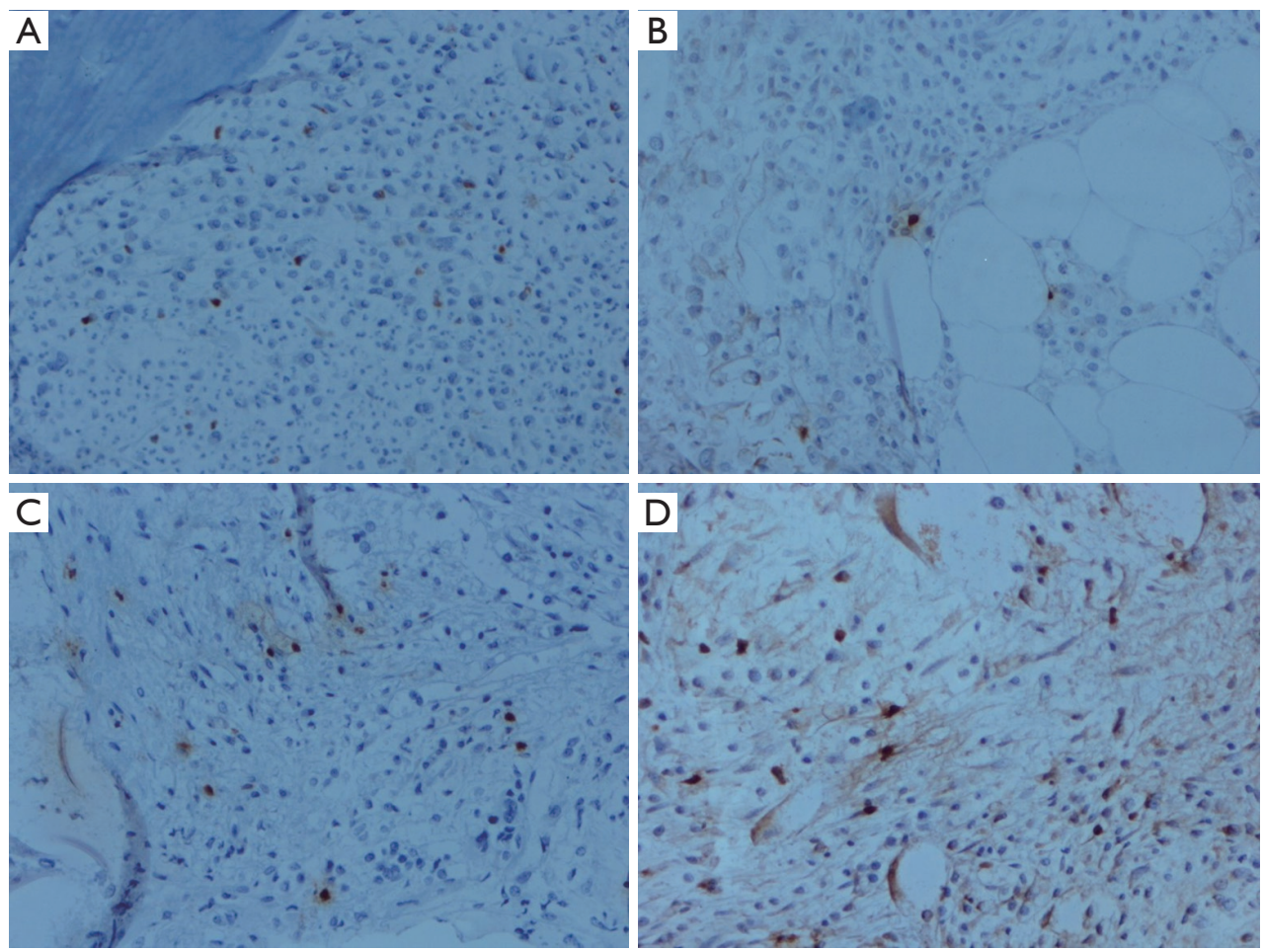

Figure 1 Bone marrow specimen showed three groups of the expression of tryptase in the mast cell: (A) healthy control group; (B) chronic phase of CML; (C) accelerated phase of CML; (D) blast phase of CML. Magnification: $\times 40$; mast cells shown in brown. CML, chronic myeloid leukemia. 

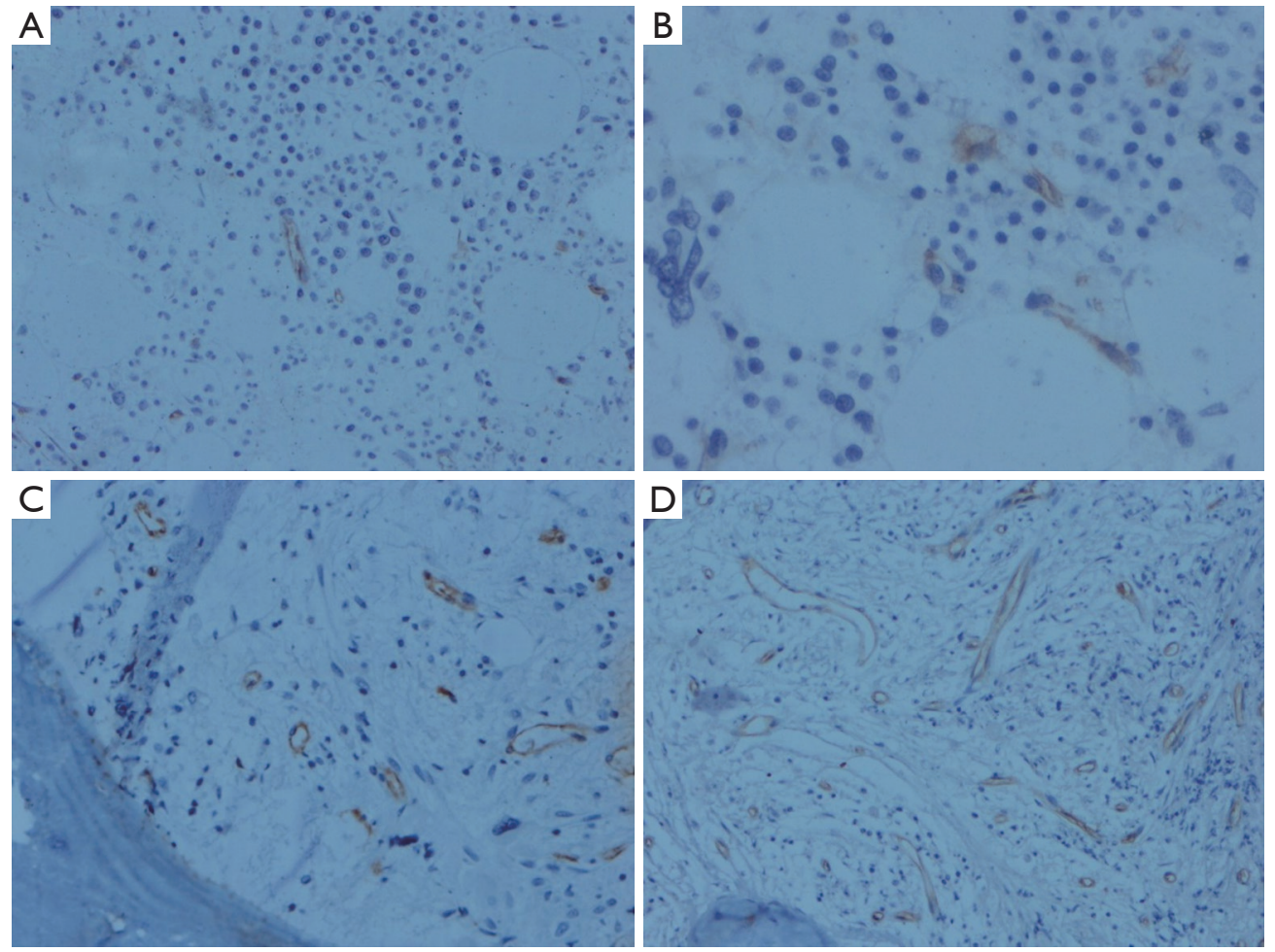

Figure 2 Bone marrow specimens stained with CD34 for microvessels of three groups: (A) healthy control group; (B) chronic phase of CML; (C) accelerated phase of CML; (D) blast phase of CML. Magnification: ×20. CML, chronic myeloid leukemia.

The relationship between tryptase-positive MCs, MVD and different phases of CML

The MVD in different phases of CML (CP 12.90 $3.76 / 40 \times$ HPF, AP $14.55 \pm 4.77 / 40 \times$ HPF, BP $25.03 \pm 4.03 / 40 \times$ HPF) were higher than which in control group $(3.13 \pm 1.22 / 40 \times$ HPF $)(\mathrm{P}<0.05)$. The difference of MVD between CP and AP group, ALLT $(23.00 \pm 2.21 / 40 \times$ HPF) and AMLT $(27.12 \pm 3.83 / 40 \times \mathrm{HPF})$ group were not significant. BP group had higher MVD than CP group $(\mathrm{P}<0.05)$. The number of tryptase-positive MCs in CP $\left(63.35 \pm 20.42 / \mathrm{mm}^{2}\right)$ and AP $\left(89.08 \pm 36.10 / \mathrm{mm}^{2}\right)$ and AMLT group $\left(307.15 \pm 86.23 / \mathrm{mm}^{2}\right)$ were higher than which in healthy controls $\left(11.00 \pm 4.13 / \mathrm{mm}^{2}\right)$ $(\mathrm{P}<0.05)$. The number of tryptase-positive MCs in AMLT group was higher than which in the $\mathrm{CP}$ group $(\mathrm{P}<0.05)$. No difference was found between ALLT group $\left(18.00 \pm 3.22 / \mathrm{mm}^{2}\right)$ and control group (Table 1).

\section{The relationship between tryptase-positive MCs, MVD and clinical parameters}

There was no correlation between the number of tryptase- positive MCs and the white blood cell, hemoglobin, and platelet counts, as well as the percentages of blast cells, eosinophils and basophils in the blood smears and bone marrow smears $(\mathrm{P}>0.05)$. There was also no correlation between the number of tryptase-positive MCs in each phase of CML and the number of hot spots in bone marrow $(\mathrm{P}>0.05)$. There was no relationship between MVD and clinical parameters mentioned above as well $(\mathrm{P}>0.05)$ (Table 3$)$.

\section{Survival analysis}

The OS and PFS of the different level of tryptase-positive and different phases of CML are shown in Figure 3. The result showed that patients with lower grade of tryptasepositive MCs in CP phase of CML survived longer OS $(\mathrm{P}=0.613)$ and $\mathrm{PFS}(\mathrm{P}=0.282)$ (Figure 3).

\section{Discussion}

This paper shows that the number of tryptase-positive MCs and the MVD increased during the development of CML. 
Table 3 The relationship between tryptase-positive mast cells, microvessel density and some clinical parameters

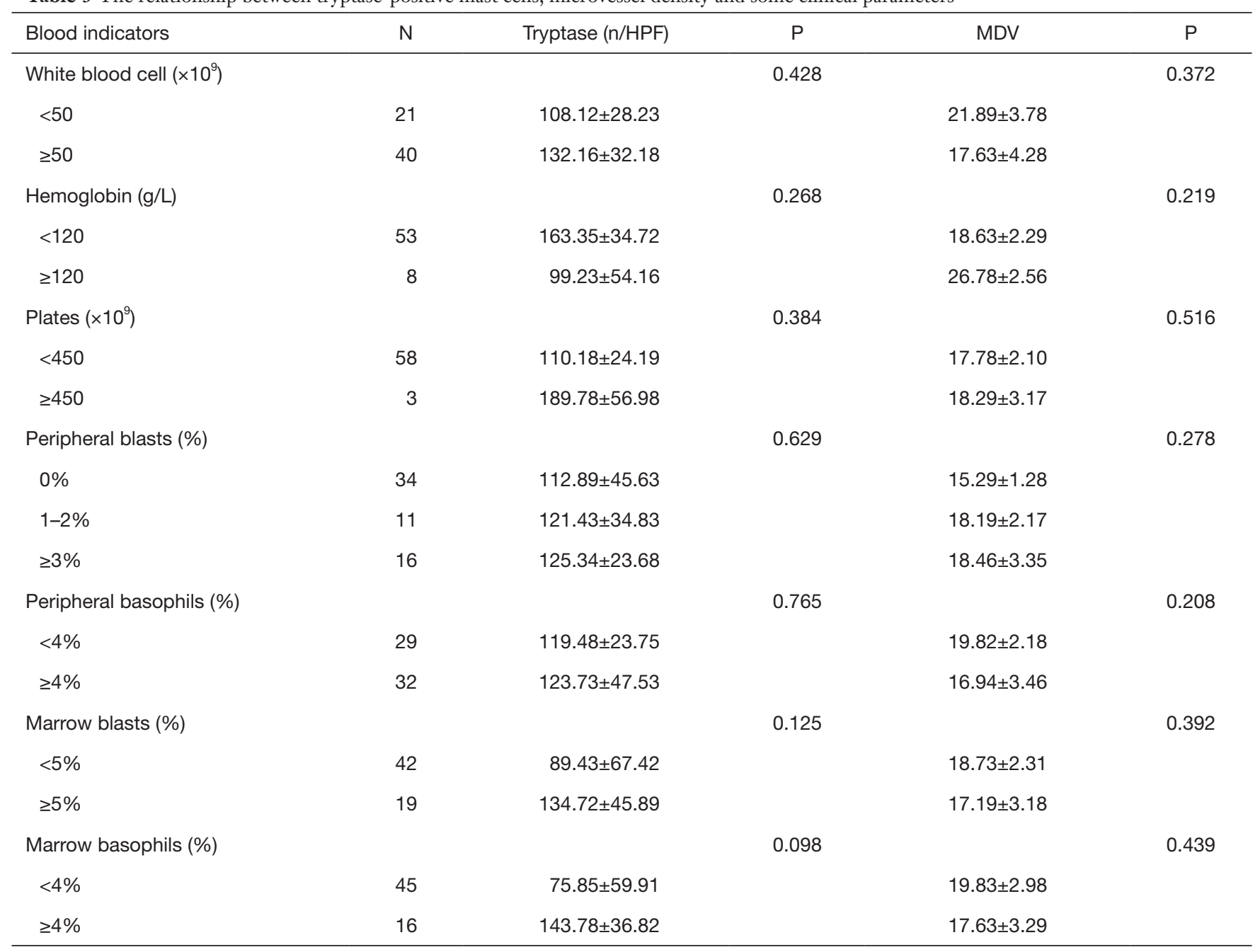
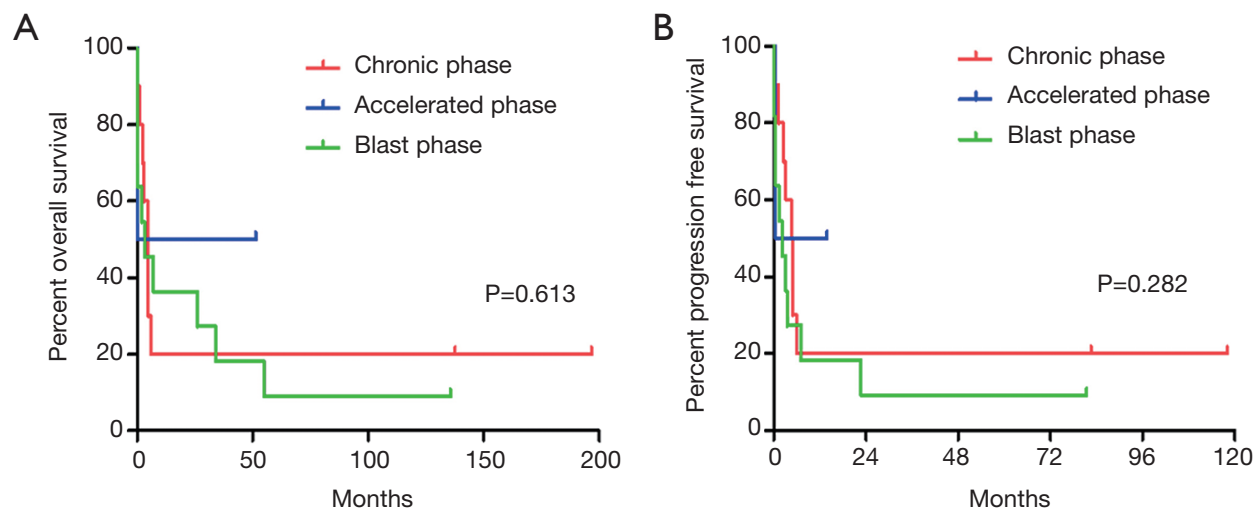

Figure 3 Kaplan-Meier curves. (A) Overall survival (OS) for chronic phase, accelerated phase, blast phase of CML; (B) progression free survival (PFS) for chronic phase, accelerated phase, blast phase of CML. CML, chronic myeloid leukemia. 
And there was the correlation between tryptase-positive MCs and bone marrow angiogenesis in the phases of CML. MCs can be attracted by tumor cells in the tumor microenvironment and produce several angiogenic factors as well as MMPs, which promote tumor vascularization and invasiveness, respectively (13). Also, MCs exert immunosuppression and stimulate immune tolerance and tumor promotion $(14,15)$. Elpek et al. reported that MC density was associated with the depth of wall invasion, lymph node metastasis, and tumor progression (stage) in patients of squamous cell carcinoma (16). Besides, Ko et al. demonstrated that MCs infiltration was potentially increased in tumors compared with normal tissues from lung, breast, and colon, by studying mouse models, suggesting that MCs might participate in tumor development (17). What's more, Ribatti et al. proved that MCs were associated with tumor progression in multiple myeloma, B-cell non-Hodgkin's lymphoma, myelodysplastic syndromes, and B-cell chronic lymphocytic leukemia $(9-12,18)$. MCs store in their secretory granules pre-formed active serine proteases, including tryptase (19). We used the anti-tryptase antibody to detect the number of tryptasepositive MCs in the bone marrow of patients with CML, and the results showed that the number of tryptase-positive MCs in CML patients increased significantly compared to the healthy control group. In the progression of the CP to the AP and to the AML transform phase, the difference in the number of tryptase-positive MCs between groups was statistically significant, suggesting that tryptase in MCs may play a role in the pathogenesis and progression of CML. Maltby et al. suggested that MC infiltration into a developing tumor triggers an "angiogenic switch". At early stages of tumor development, MCs direct angiogenesis in the developing tumor, while at later stages, the tumor cells take control of growth and angiogenesis, and growth becomes MC-independent (20). This phenomenon may explain the tryptase-positive MC counts in the ALLT phase being not significantly different from that of the healthy control group.

MCs release a variety of factors known to enhance angiogenesis, namely, heparin and histamine, a variety of cytokines, such as transforming growth factor-beta, tumor necrosis factor- $\alpha$, interleukin-8, basic fibroblast growth factor or FGF-2 and VEGF, which are implicated in normal, as well as tumor-associated angiogenesis (21). Ribatti et al. have shown that tryptase released by MCs plays a vital role in neovascularization. Direct addition of tryptase to microvascular endothelial cells cultured on Matrigel caused a pronounced increase in capillary growth, which was suppressed by specific tryptase inhibitors, and tryptase directly induced endothelial cell proliferation in a dosedependent fashion (22). We used a CD34 antibody to label microvessels in bone marrow and found that the number of microvessels was decreased, their shape was straighter, and the vascular branches were rarer in the healthy control group than in the CP of CML. The increased microvessel count, larger luminal diameter, and irregular vascular branches suggested abnormal proliferation of CML cells leading to tissue hypoxia. This outcome may stimulate VEGF to cause abnormal angiogenesis, resulting in increases in vascular size and number to maintain the oxygen concentration in the tissue. In the BP, the number of microvessels further increased, but the lumen diameter commonly showed a small-bore round shape. The morphological changes described above indicated that one change to blood vessels in CML patients is budding growth, with other changes being non-budding growth and vessel wall concavity, leading to the eventual rupture of the vascular lumen.

Many studies have shown that MCs are closely associated with angiogenesis in tumors, including hemangiomas, carcinomas, lymphomas and multiple myelomas. MCs preferentially accumulate in peripheral areas and within the surrounding connective tissue and rest near or around blood or lymphatic vessels (23). MCs are recruited and activated via several factors secreted by tumor cells, such as the c-kit receptor as well as FGF-2, and VEGF (24). However, in our study, there was no statistically significant difference between the number of tryptase-positive MCs and the MVD in CML patients. The adverse outcomes observed in our study may have been due to the following reasons: the small sample size of our research patient population, the location and ethnicity of our patients, or the specificity of CML compared to other hematologic malignancies. Schmidt et al. suggested that parallelisms between angiogenesis in solid tumors and in hematological diseases have been recognized in recent years, but we still lack fundamental insight into how vessels support hematological diseases and how this can be successfully targeted in clinical settings (25). Thus, the angiogenesis of CML is still a mystery that needs more research. There are thousands of factors that may contribute to the development of CML, and the MCs may not be the most important one, as there may be unknown but essential factors that lead to the angiogenesis of CML.

The previous literature has shown that increased $\mathrm{MC}$ number correlates with a poor prognosis in several human 
tumors, including melanoma, oral squamous carcinoma, squamous cell carcinoma of the lip, and breast cancer (11,26-28). A recent study showed that the KIT-blocking TKI imatinib produces a profound decrease in MCs in patients with $\mathrm{Ph}+\mathrm{CML}$ (29). In our study, patients in the $\mathrm{CP}$ had fewer MCs and longer survival times than the other phases of CML. Therefore, the number of MCs may have an important inverse relationship with the prognosis of CML, and MCs might act as a new target for the treatment of tumors through the selective inhibition of angiogenesis and via other mechanisms (30). The number of MCs in bone marrow may be a new parameter for the prognosis of CML.

In conclusion, our study found that there was no statistically significant difference between the number of tryptase-positive MCs and the MVD in CML patients. The microenvironment of tumors is too complicated to be clarified; however, interventions targeting the microenvironment may be promising therapeutic approaches to delay the progression of the disease. The increasing number of tryptase-positive MCs along with the progression of CML may herald the transformation from CML into AML. The number of tryptase-positive MCs may play as a new monitoring indicator which is easy operated and with the value of assisting diagnosis and predicting the transformation and prognosis of CML.

\section{Acknowledgments}

We would like to thank all the volunteers who took part in this study.

Funding: This work was supported by the National Natural Science Foundation of China (81570174), the Jiangsu Provincial Medical Innovation Team (CXTDA2017046), the Jiangsu Provincial Medical Youth Talent (QNRC2016039), and the Technique Development Foundation of Nan Jing (Outstanding Youth Foundation, JQX16099, 17057).

\section{Footnote}

Conflicts of Interest: All authors have completed the ICMJE uniform disclosure form (available at http://dx.doi. org/10.21037/tcr.2019.09.29). The authors have no conflicts of interest to declare.

Ethical Statement: The authors are accountable for all aspects of the work in ensuring that questions related to the accuracy or integrity of any part of the work are appropriately investigated and resolved. The study protocol was approved by the Ethical and Protocol Review Committee of Nanjing University. All procedures performed in studies involving human participants were in accordance with the ethical standards of Nanjing University and with the 1964 Helsinki declaration and its later amendments or comparable ethical standards. Written informed consent was obtained from all patients.

Open Access Statement: This is an Open Access article distributed in accordance with the Creative Commons Attribution-NonCommercial-NoDerivs 4.0 International License (CC BY-NC-ND 4.0), which permits the noncommercial replication and distribution of the article with the strict proviso that no changes or edits are made and the original work is properly cited (including links to both the formal publication through the relevant DOI and the license). See: https://creativecommons.org/licenses/by-nc-nd/4.0/.

\section{References}

1. Jabbour E, Kantarjian H. Chronic myeloid leukemia: 2018 update on diagnosis, therapy and monitoring. Am J Hematol 2018;93:442-59.

2. Chereda B, Melo JV. Natural course and biology of CML. Ann Hematol 2015;94:S107-21.

3. Askmyr M, Ågerstam H, Lilljebjörn H, et al. Modeling chronic myeloid leukemia in immunodeficient mice reveals expansion of aberrant mast cells and accumulation of pre-B cells. Blood Cancer J 2014;4:e269.

4. Saponaro C, Malfettone A, Ranieri G, et al. VEGF, HIF1a Expression and MVD as an Angiogenic Network in Familial Breast Cancer. PLoS One 2013;8:e53070.

5. Marech I, Ammendola M, Gadaleta C, et al. Possible biological and translational significance of mast cells density in colorectal cancer. World J Gastroenterol 2014;20:8910-20

6. de Souza DA, Toso VD, Campos MR de C, et al. Expression of Mast Cell Proteases Correlates with Mast Cell Maturation and Angiogenesis during Tumor Progression. PLoS One 2012;7:e40790.

7. Ammendola M, Sacco R, Zuccalà V, et al. Mast Cells Density Positive to Tryptase Correlate with Microvascular Density in both Primary Gastric Cancer Tissue and Loco-Regional Lymph Node Metastases from Patients That Have Undergone Radical Surgery. Int J Mol Sci 2016;17:1905.

8. de Souza Junior DA, Santana AC, da Silva EZM, et al. The Role of Mast Cell Specific Chymases and Tryptases in 
Tumor Angiogenesis. BioMed Res Int 2015;2015:142359.

9. Ribatti D, Molica S, Vacca A, et al. Tryptase-positive mast cells correlate positively with bone marrow angiogenesis in B-cell chronic lymphocytic leukemia. Leukemia 2003;17:1428-30.

10. Ribatti D, Polimeno G, Vacca A, et al. Correlation of bone marrow angiogenesis and mast cells with tryptase activity in myelodysplastic syndromes. Leukemia 2002;16:1680-4.

11. Molica S, Vacca A, Crivellato E, et al. Tryptase-positive mast cells predict clinical outcome of patients with early B-cell chronic lymphocytic leukemia. Eur J Haematol 2003;71:137-9.

12. Ribatti D, Vacca A, Marzullo A, et al. Angiogenesis and mast cell density with tryptase activity increase simultaneously with pathological progression in B-cell non-Hodgkin's lymphomas. Int J Cancer2000;85:171-5.

13. Ribatti D, Crivellato E. The Controversial Role of Mast Cells in Tumor Growth. Bari: Elsevier, 2009.

14. Ullrich SE, Nghiem DX, Khaskina P. Suppression of an Established Immune Response by UVA? A Critical Role for Mast Cells. Photochem Photobiol 2007;83:1095-100.

15. Grimbaldeston MA, Nakae S, Kalesnikoff J, et al. Mast cell-derived interleukin 10 limits skin pathology in contact dermatitis and chronic irradiation with ultraviolet B. Nat Immunol 2007;8:1095-104.

16. Elpek GO, Gelen T, Aksoy NH, et al. The prognostic relevance of angiogenesis and mast cells in squamous cell carcinoma of the oesophagus. J Clin Pathol 2001;54:940-4.

17. Ko EA, Sanders KM, Zhou T. A transcriptomic insight into the impacts of mast cells in lung, breast, and colon cancers. OncoImmunology 2017;6:e1360457.

18. Ribatti D, Vacca A, Nico B, et al. The role of mast cells in tumour angiogenesis. Br J Haematol 2001;115:514-21.

19. Ribatti D, Ranieri G. Tryptase, a novel angiogenic factor stored in mast cell granules. Exp Cell Res 2015;332:157-62.

20. Maltby S, Khazaie K, McNagny KM. Mast cells in tumor growth: Angiogenesis, tissue remodelling and immunemodulation. Biochim Biophys Acta 2009;1796:19-26.

21. Gilfillan AM, Metcalfe DD. Mast cell biology: contemporary and emerging topics. Maryland: Springer Science, 2011.

22. Ribatti D, Finato N, Crivellato E, et al. Neovascularization and mast cells with tryptase activity increase simultaneously with pathologic progression in human endometrial cancer. Am J Obstet Gynecol 2005;193:1961-5.

23. Marichal T, Tsai M, Galli SJ. Mast Cells: Potential Positive and Negative Roles in Tumor Biology. Cancer Immunol Res 2013;1:269-79.

24. Ammendola M, Leporini C, Marech I, et al. Targeting Mast Cells Tryptase in Tumor Microenvironment: A Potential Antiangiogenetic Strategy. BioMed Res Int 2014;2014:154702.

25. Schmidt T, Carmeliet P. Angiogenesis: A Target in Solid Tumors, Also in Leukemia? Hematology 2011;2011:1-8.

26. Iamaroon A, Pongsiriwet S, Jittidecharaks S, et al. Increase of mast cells and tumor angiogenesis in oral squamous cell carcinoma: Mast cells and angiogenesis in oral cancer. J Oral Pathol Med 2003;32:195-9.

27. Rojas IG, Spencer ML, Martinez A, et al. Characterization of mast cell subpopulations in lip cancer. J Oral Pathol Med 2005;34:268-73.

28. Groot Kormelink T, Powe DG, Kuijpers SA, et al. Immunoglobulin free light chains are biomarkers of poor prognosis in basal-like breast cancer and are potential targets in tumor-associated inflammation. Oncotarget 2014;5:3159-67.

29. Cerny-Reiterer S, Rabenhorst A, Stefanzl G, et al. Longterm treatment with imatinib results in profound mast cell deficiency in $\mathrm{Ph}+$ chronic myeloid leukemia. Oncotarget 2015;6:3071-84.

30. Al-Husein B, Abdalla M, Trepte M, et al. Antiangiogenic Therapy for Cancer: An Update. Pharmacotherapy 2012;32:1095-111.
Cite this article as: $\mathrm{Xu} \mathrm{P}$, Zhang $\mathrm{C}$, Wang $\mathrm{Y}, \mathrm{Wu} \mathrm{H}$, Cheng S, Fan X, Zhang Q. Increased number of mast cells in the bone marrow of chronic myeloid leukemia may herald the pending myeloid transformation-the mast cell is an indicator of myeloid transformation. Transl Cancer Res 2019;8(5):2121-2129. doi: $10.21037 /$ tcr.2019.09.29 